\title{
Impact of Coagulation Agents on the Performance of Flotation Unit for the Treatment of Industrial Waste Water
}

\author{
Salam J. Bash AlMaliky \\ $\mathrm{PhD}$, Associate Prof. \\ College of Environmental Engineering/ AlMustansiriya University-IRAQ \\ Faculty and Leader in Residence/ Ohio University-USA
}

\begin{abstract}
The performance of a batch laboratory scale induced air flotation (IAF) unit in controlling fat, oil, and Grease (FOG) and five days biological oxygen demand $\left(\mathrm{BOD}_{5}\right)$ in effluents of a meats processing \& packing industry, was tested using two types of coagulation agents (Alum and Bentonite clay) and three air flow rates. Prior to coagulation, air flow rates of 3 and $5 \mathrm{l} / \mathrm{min}$ were the best for having FOG removal efficiencies of $60 \%$ and $62 \%$, respectively. Significant improvements in these were measured $(94.5 \%$ and $96.2 \%$ for the mentioned air flow rates respectively) after the addition of $0.5 \mathrm{~g} / 1$ Alum, while extra $0.2 \mathrm{~g} / 1$ bentonite clay as coagulation aid had achieved efficiencies of $96.3 \%$ and $99.3 \%$ for these air flow rates respectively. Also, the addition of $0.5 \mathrm{~g} / \mathrm{l}$ Alum had improved the $\mathrm{BOD}_{5}$ reduction efficiency from $54 \%$ to $65 \%$ and from $63 \%$ to $71 \%$, for air flow rates of 3 $1 / \mathrm{min}$ and $5 \mathrm{l} / \mathrm{min}$ respectively, as compared with no Alum cases. Higher $\mathrm{BOD}_{5}$ removal efficiencies of $73 \%$ and $78 \%$ were measured for the two air flow rates respectively, by aiding the coagulation with $0.2 \mathrm{~g} / \mathrm{l}$ bentonite clay. At least $25 \%$ saving of flotation time was proved by the addition of bentonite clay to achieve final results, similar to these with Alum only for both $\mathrm{FOG}$ and $\mathrm{BOD}_{5}$, which in turn may save part of the operational costs.

Author would like to acknowledge the logistic and technical support of the Ins. of International Education IIE, Scholars Rescue Fund SRF and Russ College of Eng. / OU.
\end{abstract}

Keywords: Bentonite clay, Coagulation, Food Industry, FOG, Induced Air Flotation

The food-processing industry utilizes water to meet its individual day-to-day needs. Fifty percent of the water used in the fruit and vegetable sector is for washing and rinsing. The meat processing sector has minimum requirements set by the United States Department of Agriculture (USDA) on the amount of water required to clean poultry products. Water is the primary ingredient in products for the beverage and fermentation sector, and it is also utilized by dairies as the standard cleaning agent for process machinery (WEF, 2008).

Food industries waste streams vary per facility, but they can be generalized into the following: process wastewaters, carcasses and skeleton waste, rejected or unsatisfactory animals, FOG, animal feces, blood, and eviscerated organs. Potential source of FOG in these industries include meat processors and renders, dairy processors, vegetable cookers and processors, edible oil producers, and nut and seed processors. The BOD for all food-processing wastewater is relatively high compared to other industries (Shahidul Islam, Saleha Khan and Masaru Tanaka, 2004). A high BOD level indicates that a wastewater contains elevated amounts of dissolved and/or suspended solids, minerals, and organic nutrients containing nitrogen and phosphorus.

In reference to food industry wastewater, treatment processes have to assure first of all, required quality of discharged effluents. Also, costs analysis, and possible utilization of substances contained in wastewater are taken into consideration (WBG, 2007). Experience of many plants which process raw materials of animal origin indicates that the best results of efficient technological wastewater treatment are achieved with combination of physical methods (i.e. screens, sieves, sedimentation tanks or flotation units) with chemical treatment. Fat flotation is often combined with addition of chemicals acting as coagulants and precipitants of pollutants (Begt, 2002). Some of the additional benefits for the application of ferric or aluminum salts in wastewater treatment are: precipitation of sulfur compounds, easier sludge dewatering, increased efficiency in elimination of pollutants, and reduction in energy consumption in the biological process applied as final stage of treatment. It is also important to understand some disadvantages of this methodology such as that, the addition of treatment chemicals may increase the total volume of sludge, large amounts of chemicals may need to be transported to the treatment location and polymers used can be expensive (Sonia, Juan and Francisco, 2008).

IAF is a water treatment process that clarifies wastewaters (or other waters) by the removal of suspended matter such as oil or solids. The removal is achieved by injecting air bubbles into the water or wastewater in a flotation tank or basin. The small bubbles adhere to the suspended matter causing the suspended matter to float to the surface of the water where it may then be removed by a skimming device. The feed water to the IAF float tank is 
often (but not always) dosed with a coagulant (such as ferric chloride or Alum) to flocculate the suspended matter (Hayatdavoudi, 2006). Some IAF unit designs utilize parallel plate packing material to provide more separation surface and therefore to enhance the separation efficiency of the unit.

Oil droplets are negatively charged due to charged surfactants or adsorption of hydroxyl ions. Repulsive electrostatic forces prevent coalescence. Introducing an opposite charge modifies the negative charge, encouraging oil droplets to coagulate and assisting in the attachment of coagulated oil droplets to the negative air bubbles (DA Rosa and Rubio, 2005). Aluminum salts are effective coagulating agents and are widely used in wastewater treatment (Deglon, 2005). When added to water, $\mathrm{Al}^{+3}$ hydrates and reacts to form monomers, polymers and solid precipitates. These hydrophobic polymers have a large surface area, an amorphous structure and a positive charge. This allows for adsorption onto negative oil surfaces, rendering them insoluble. Charge neutralization leads to colloid destabilization.

The goal of this paper was to determine the impact of two types of coagulants; Alum and Bentonite clay on the performance of an IAF unit that handles effluents of meats processing \& packing industry that serve meats, poultry, seafood and cheeses. Characteristics of meats processing \& packing industry waste water were summarized by table 1 .

\section{Experimental setup and procedure}

A batch laboratory scale tank $(50 \times 30 \times 40 \mathrm{~cm})$ was made for the air flotation process of industrial waste waters, with the devices listed in table 2 connected as shown in fig.1. Three sampling holes were made at the side of tank at elevations of $(5,15$, and $30 \mathrm{~cm})$ considering for the bottom, middle and top layers of the flotation tank that was filled to the height of $(35 \mathrm{~cm})$ with waste water under consideration. Three air flow rates $(1,3$, and 5 $1 / \mathrm{min}$ ) were applied for $(120 \mathrm{~min})$ duration each. The wastewater $\mathrm{pH}$ was kept in the range 5.0-7.0 using $\mathrm{H}_{2} \mathrm{SO}_{4}$. Analysis of FOG, $\mathrm{BOD}_{5}$, and $\mathrm{pH}$ were determined according to the standard methods (APHA, 2010).

Prior to the application of any coagulant, $\mathrm{FOG}$ and $\mathrm{BOD}_{5}$ were measured at each of the three layers of flotation tank (top, middle and bottom) as a result of the application of each one of the air flow rates $(1,3$, and $51 / \mathrm{min})$ at periods of 30,60, 90, and 120 minutes from the start of process.

Impact of Alum as a coagulation agent was studied by repeating the steps mentioned above with the use of 0.2 , 0.4 , and $0.5 \mathrm{~g} / 1$ doses of Alum, separately. The third phase of experimental procedure was to study the impact of adding bentonite clay as coagulation aid with the Alum, and repeating the above sampling scenario.

\section{Results and Discussions}

First set of flotation results regarding the effect of different air flow rates $(1,3$, and $51 / \mathrm{min})$, on the FOG reduction process. For all three air flow rates, and as time passes, a clearer bottom layer appears; i.e. less oil concentration as shown in fig. 2. Oil/water separation occurs in a faster manner for the first $60 \mathrm{~min}$., compared with that occurs for the rest time. The separation pursues slowly after the expiry of 90 min. FOG removal efficiency was raised from $44 \%$ to $60 \%$ by increasing air flow rate from 1 to $3 \mathrm{l} / \mathrm{min}$, while afterward no significant increase in removal efficiency was achieved with the higher air flow rate of $5 \mathrm{l} / \mathrm{min}(62 \%)$.

The second set of flotation tests were meant to determine the effect of adding different doses of Alum $(0.2,0.4$, and $0.5 \mathrm{~g} / \mathrm{l}$ ) as a coagulant on the FOG removal process for the three air flow rates mentioned above (fig. 3-5). These figures remark clearly that the addition of Alum has significantly increased the reduction performance of IAF unit for FOG, as summarized in table 3. It was clearly noticed from these figures that although FOG reduction rates increase rapidly for the first 90 minutes, they tend to diminish afterword and by the expiry of about 120 minutes, it gives no benefit (regarding FOG removal) pursuing the operation of IAF unit.

Third set of tests was made to determine the impact of bentonite clay doses of $0.1,0.2$ and $0.3 \mathrm{~g} / 1$ addition to the system (plus $0.5 \mathrm{~g} / \mathrm{l}$ Alum, as it was proved for having the best results) to serve as coagulation aid for the IAF system that was operated with $5 \mathrm{1} / \mathrm{min}$ air flow rate. Fig. 6 had shown significant role of bentonite clay in enhancing the FOG removal efficiency. This may be attributed to the ability of bentonite to adsorb relatively large amounts of protein molecules from aqueous solutions Efficiencies of $96.8 \%$ and $99.3 \%$ were achieved by the addition of $0.1 \mathrm{~g} / 1$ and $0.2 \mathrm{~g} / \mathrm{l}$ of bentonite clay respectively. The addition of $0.3 \mathrm{~g} / \mathrm{l}$ bentonite clay has not proved any remarkable gain in enhancing the removal efficiency that may compensate the cost of its addition. Another indication on that regard was that the use of bentonite clay had not enhanced the removal efficiency, but it accelerated the removal process and made it possible to get similar performance as with the case of Alum only at shorter times. Also, Fig. 6 has shown that FOG content of about $5 \mathrm{mg} / 1$ was achieved via the use of $0.2 \mathrm{~g} / 1$ bentonite clay in addition to $0.5 \mathrm{~g} / 1$ Alum after the expiry of about 90 minutes, while with the same dose of Alum the FOG was measured as $9.5 \mathrm{mg} / \mathrm{l}$ after 120 minutes of operation under the same operational parameters. This 
time saving (about 25\%) may count for the compensation of the use of coagulation aids.

In addition to the role of FOG removal, an IAF unit typically serves; it was proven that considerable BOD removals have been accomplished via well operated unit. Prior to the use any coagulant, the $\mathrm{BOD}_{5}$ was reduced from $650 \mathrm{mg} / \mathrm{l}$ to about $300 \mathrm{mg} / \mathrm{l}$ and $240 \mathrm{mg} / \mathrm{l}$ via air flotation rates of $3 \mathrm{l} / \mathrm{min}$ and $5 \mathrm{l} / \mathrm{min}$ respectively, while $\mathrm{BOD}_{5}$ of $228 \mathrm{mg} / 1$ and $189 \mathrm{mg} / \mathrm{l}$ were achieved via the dosing of $0.5 \mathrm{~g} / \mathrm{l}$ Alum for the two air flow rates respectively. Greater gains on that regard were achieved by aiding the coagulation with bentonite clay, where $\mathrm{BOD}_{5}$ reduction efficiencies of $73 \%$ and $78 \%$ were measured for the air flow rates of $31 \mathrm{lmin}$ and $51 / \mathrm{min}$ respectively. This indicates that the majority of BOD constituent in the waste water of such industries like meat canning and processing was the insoluble FOG.

\section{Conclusions}

FOG released with the effluent of industrial activities is a problem when disposed to sanitary sewer system where it tends to stick to the walls of sewer pipes or to the surface streams where it badly alters the water quality. FOG posses a natural stickiness that leads to the formation of a grease layer in the biological treatment units. IAF unit that operates at 3-5 1/min air flow rates where proved to achieve high FOG removal efficiencies via the use of $0.5 \mathrm{~g} / \mathrm{l}$ Alum plus $0.2 \mathrm{~g} / \mathrm{l}$ bentonite clay as coagulation agents, hence values of $96.3 \%$ and $99.3 \%$ were feasible for the $3 \mathrm{l} / \mathrm{min}$ and $5 \mathrm{l} / \mathrm{min}$ air flow rates respectively.

Significant BOD removals were concluded via the combination of operation parameters mentioned above, where about $73 \%$ and $78 \%$ of $\mathrm{BOD}_{5}$ were removed respectively.

In addition to the enhancement of removal efficiency regarding FOG and BOD, the use of bentonite clay as a coagulation aid with Alum has proved the save of about $25 \%$ of IAF operation time.

\section{References}

APHA. (2010). Standard Methods for the Examination of Water and Wastewater, Edited by Lenore S. Clesceri, Arnold E. Greenberg and Andrew D. Eaton. 20th Edition.

Begt H. (2002). Chemical Waste Water Treatment- Old and New application. Preceding of KEMIPOL SA Seminar. Copenhagen.

DA Rosa JJ and Rubio J. (2005). The FF (flocculation-flotation process). Minerals Engineering. www.elsvier.com/locate/mineng.

Deglon D. (2005). The Effect of Agitation on the Flotation of Platinum Ores, Minerals Engineering. Vol.18 No.8, 2005

Hayatdavoudi A.. (2006). Removing Oil and Grease from Produced Water Using Micro-Bubble Flotation Technique. Offshore Technology Conference, Texas, USA.

Shahidul Islam, Saleha Khan and Masaru Tanaka. (2008). Waste loading in shrimp and fish processing effluents: potential source of hazards to the coastal and near shore environments. Marine Pollution Bulletin. Vol. 49, Issues 1-2, pp.103-110.

Sonia Suarez, Juan M. Lema and Francisco Omil. (2008). Pre-treatment of hospital wastewater by coagulation-flocculation and flotation. Journal of Bioresource Technology. Vol. 100, Issue 7.

Water environment federation (WEF). (2008). Industrial waste water management, treatment, and disposal. $3^{\text {rd }}$ edition. McGraw Hill Company.

World Bank Group (WBG). (2007). Pollution Prevention Hand Book. Environmental, Health and Safety Guidelines. www.ifc.org/ifcext/enviro.nsf. 
Table 1. Raw Wastewater Characteristics of the meat canning and processing industry

\begin{tabular}{|l|l|}
\hline Characteristic & Amount \\
\hline BOD5 (mg/l) & 650 \\
\hline COD $(\mathrm{mg} / \mathrm{l})$ & 1512 \\
\hline TSS $(\mathrm{mg} / \mathrm{l})$ & 1200 \\
\hline FOG & 250 \\
\hline Temperature C & $24-25$ \\
\hline pH & $6.5-8$ \\
\hline
\end{tabular}

Table 2. List of devices connected to IAF unit under study

\begin{tabular}{|l|l|}
\hline Device & Specification \\
\hline Air compressor & MD35-20,31 1/min output at 8 bars \\
\hline pressure regulator & Amstar PR354G \\
\hline Rotameter & KDG, $0-22 \mathrm{l} / \mathrm{min}$ \\
\hline
\end{tabular}

Table 3. FOG removal efficiencies for different Alum doses and air flow rates.

\begin{tabular}{|c|c|c|c|}
\hline \multirow{2}{*}{ Alum dose (g/l) } & \multicolumn{3}{|c|}{ Removal efficiency\% } \\
\cline { 2 - 4 } & $11 / \mathrm{min}$ & $31 / \mathrm{min}$ & $51 / \mathrm{min}$ \\
\hline 0.2 & 53.6 & 66.8 & 70.8 \\
\hline 0.4 & 60.4 & 75.2 & 84.4 \\
\hline 0.5 & 80.3 & 94.5 & 96.2 \\
\hline
\end{tabular}




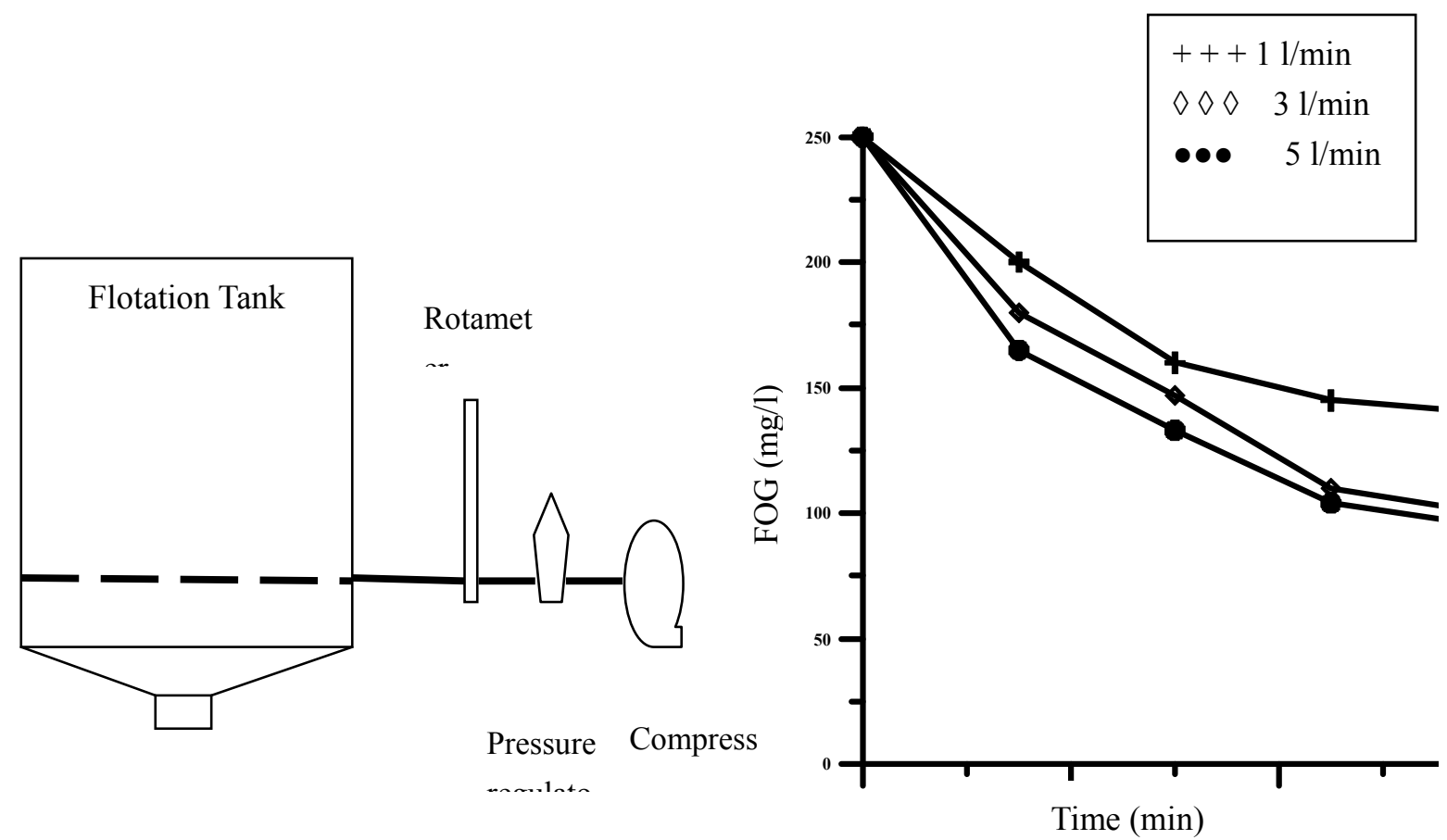

Figure 1. Schematic of IAF system under study

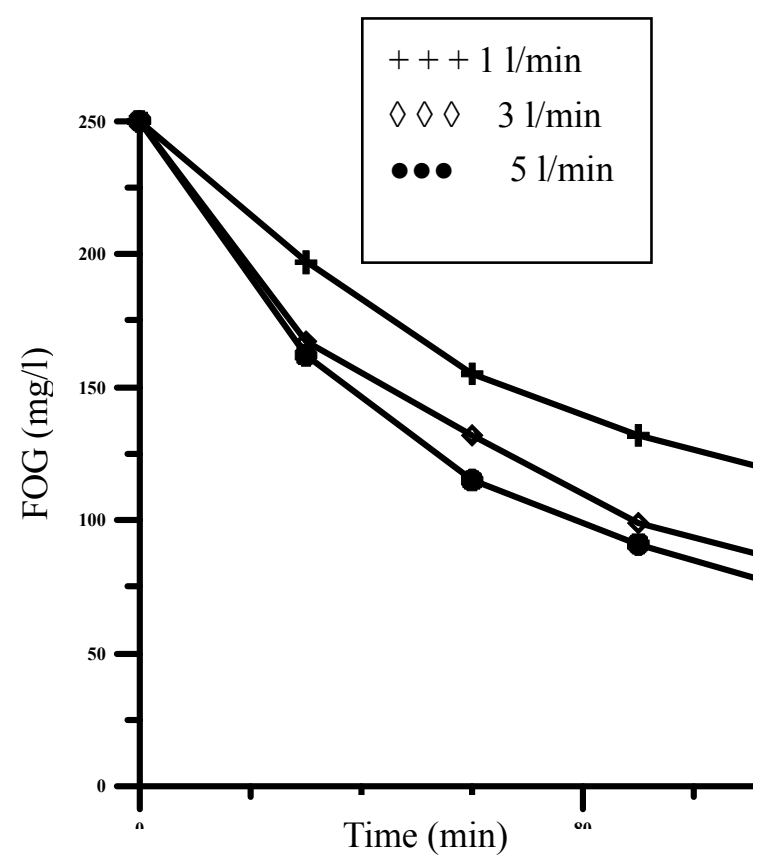

Figure 3. FOG concentrations vs. operation time Alum $0.2 \mathrm{~g} / 1$
Figure 2. FOG at bottom layer of IAF unit vs. operation time (No coagulant).

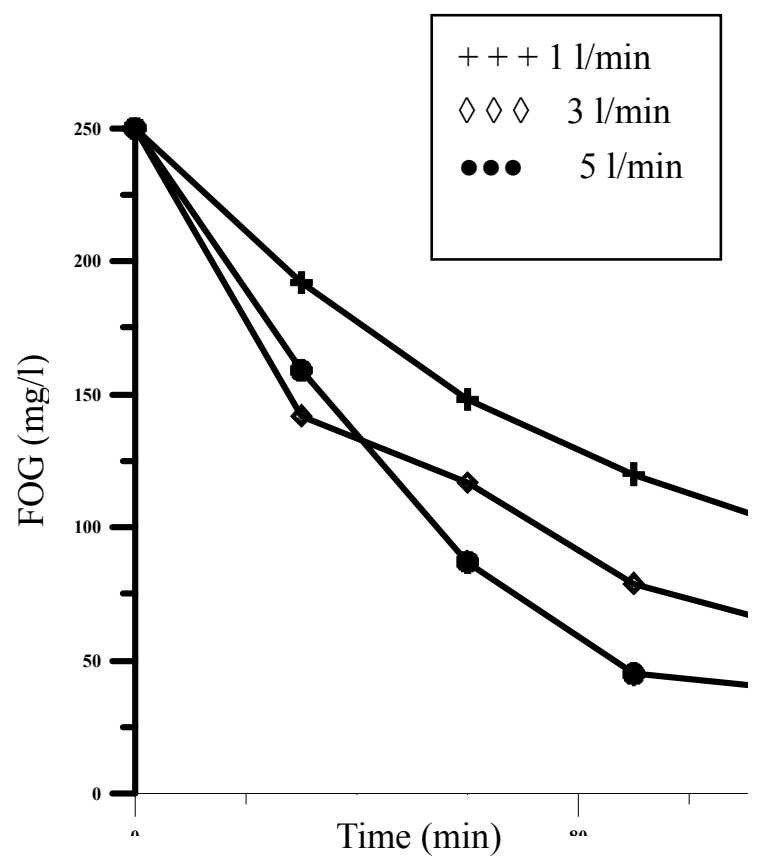

Figure 4. FOG concentrations vs. operation time Alum $0.4 \mathrm{~g} / 1$ 


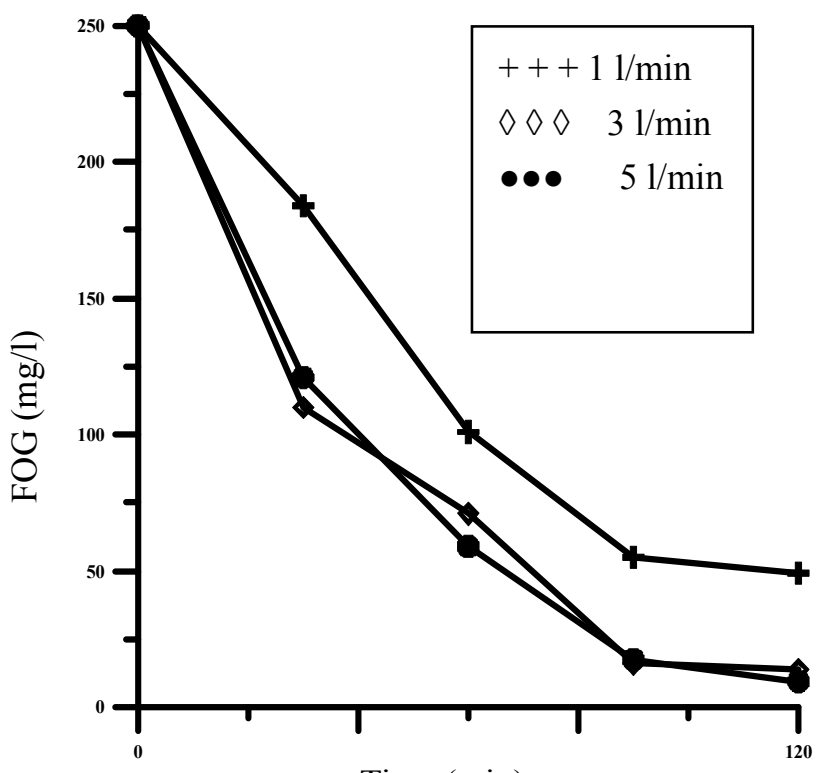

Time (min)

Figure 5. FOG concentrations vs. operation time Alum $0.5 \mathrm{~g} / 1$

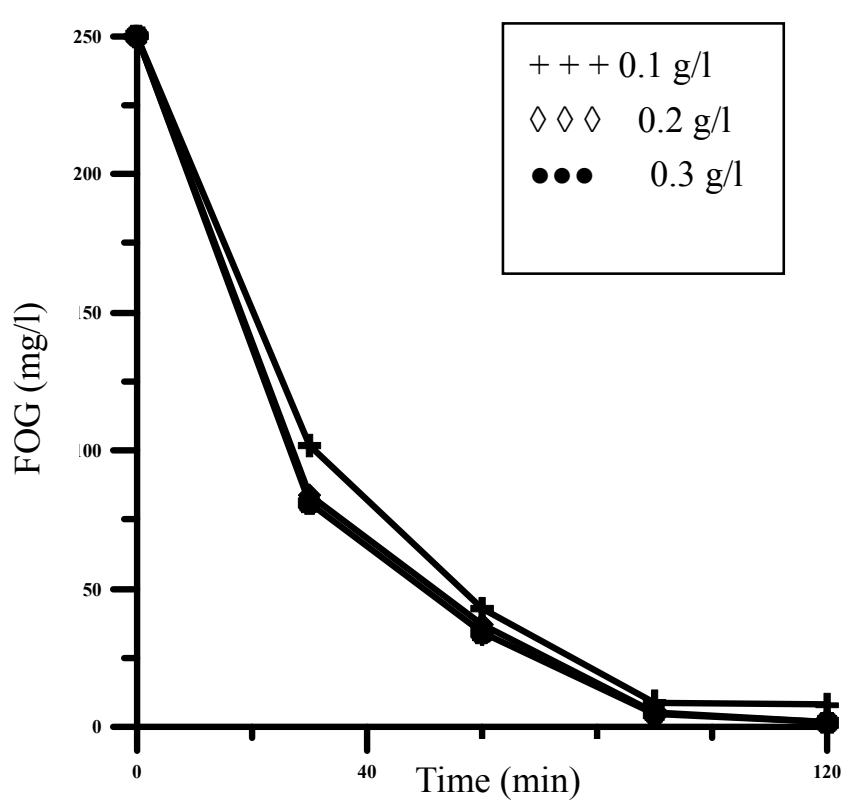

Figure 6. effect of Bentonite clay addition on FOG concentrations (5 1/min air flow rate and Alum $0.5 \mathrm{~g} / \mathrm{l})$ 